\title{
Spatial-temporal variations of Köppen climate types in China
}

\author{
Ting Wang, Daowei Zhou, and Xiangjin Shen*
}

Northeast Institute of Geography and Agroecology, Chinese Academy of Sciences, Changchun, China

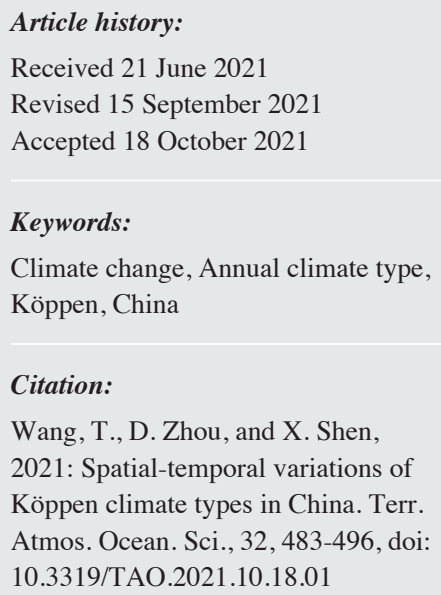

Citation:

Wang, T., D. Zhou, and X. Shen, 2021: Spatial-temporal variations of Köppen climate types in China. Terr. Atmos. Ocean. Sci., 32, 483-496, doi: 10.3319/TAO.2021.10.18.01

\begin{abstract}
The classification of Köppen climate type has been widely used to identify regional climate change. This study investigated the changes of Köppen climate type over China during 1964 - 2015. On average, the arid climate was located in the northwest, tropical climate, temperate climate, and cold climate were distributed in the east from south to north along the latitude, and polar climate was concentrated on the Tibetan Plateau. Comparing Köppen climate types during 1964 - 1989 and 1990 - 2015, we found that cold climate with dry winter was replaced by a cold steppe climate in Northeast China and North China, warm summer was replaced by cold summer in Northeast China and the Tibetan Plateau, tundra climate was substituted by cold climate in the Tibetan Plateau, and cold climate was replaced by temperate climate in Central China and East China. Our results showed that the arid climate expanded eastward and southward, which may have resulted from a decrease in precipitation. Owing to the increase in temperature, the climate zones moved northward. This study provides valuable insights for government decision-makers in formulating crop planting systems, water resource management, and land use planning.
\end{abstract}

\section{INTRODUCTION}

Climate is the average state of the atmosphere in a region, which is affected by both internal factors and external forces. Anthropogenic and natural forces cause climate change with spatial variations (Zhai et al. 2014; Zhou et al. 2016; Shen et al. 2020). Over the past century, global warming has been the most significant feature of climate change, and human factors are the primary cause (Foley et al. 2005). Climate change can have an important impact on human life, agricultural production, environmental conditions, and the social economy (Bai et al. 2020; Li et al. 2020; Liu et al. 2020; Shen et al. 2021a, b; Wang et al. 2021). Many measurements are considered when evaluating climate change, such as temperature, precipitation, relative humidity, wind speed, and solar radiation (Wang et al. 2020). However, each of these measurements only analyzes a single aspect of climate change, whereas the climatic conditions of a region are the result of the comprehensive influence of various meteorological factors. To combine related weather conditions, researchers have created various classifications, such as the Köppen climate classification.

\footnotetext{
* Corresponding author

E-mail: shenxiangjin@iga.ac.cn
}

The Köppen climate classification system, established by Köppen in the early 20th century, was the first quantitative climate classification system (Rubel et al. 2017). Köppen established five climate zones based on vegetation type and regarded this as the first-level climate classification. Based on the first-level climate classification, the second- and third-level classifications are carried out using the monthly, seasonal, and annual distribution characteristics of temperature and precipitation (Peel et al. 2007). Given the abundant data available, the simplicity of the Köppen standards, and their adaptability to grasslands, deserts, tundra, forests, and other landscapes, the Köppen climate classification has been widely used in agriculture, climate, meteorology, and the hydrological environment (Belda et al. 2014).

To date, applications of the Köppen climate classification have mainly focused on the following aspects: (1) using meteorological data on different time scales to study climate distribution characteristics globally and regionally (Kottek et al. 2006; Alvares et al. 2013); (2) investigating climate change over different spatial and time scales, including exploration of changes between paleoclimate and modern climate, changes in the present climate, and prediction of future climate change (Feng et al. 2012; Zhang and Yan 2014; Yoo and Rohli 2016; Rajaud and de Noblet-Ducoudré 2017; 
Dubreuil et al. 2019); (3) applying the Köppen climate classification to the output of various models and comparing it with the classification based on existing datasets to evaluate these models (McMahon et al. 2015; Tapiador et al. 2019); and (4) combining it with other studies, such as those on biological communities, soil types, particulate matter, and runoff to further understand the impact of climate change on the environment (Pražnikar 2017; Wang et al. 2019).

As the third largest country in the world, China has a unique climate zoning scheme based on regional characteristics. To compare the climate of China with the global climate, many researchers have used the Köppen climate classification to study the distribution and changes of climate in China. Kim et al. (2008) used the Köppen climate classification to study the distribution and changes in the arid climate of North China. Subsequently, Baker et al. (2010) combined the Köppen climate classification with ecology to study the impact of climate change on ecological regions. Recently, Chan et al. (2016) predicted the changes in the Köppen climate zones over China in the 21st century. Previous studies investigating the Köppen climate classification in China have mostly focused on the distribution of the long-term averaged Köppen climate type, ignoring the dynamic change of the Köppen climate type in the context of global climate change. The annual climate type is valuable for observing the boundaries, evolution, and diversity of climate in a region. The sites with the most frequent occurrence of a certain climate type are climate-stable areas, and the sites with varied annual climate types are climate transition zones. However, no attempts have been made to explore the characteristics of climate change in China from the perspective of frequency changes in the annual Köppen climate type. The Köppen climate classification is defined based on a series of temperature and precipitation thresholds. Once the temperature or precipitation in a certain year exceeds this threshold, the climate type may be inconsistent with the average climate type. Based on the correlation between the Köppen climate type and natural vegetation pattern, the study of its changes is valuable for understanding the impact of climate change on the distribution of biological communities. Moreover, this study can provide a scientific basis for agricultural planning, urban infrastructure management, and forestry layout. Therefore, it is important to study the changes in the Köppen climate type, including frequency changes. Changes in temperature and precipitation show distinct regional differences in China (Shen et al. 2014; Xu et al. 2019). How will these changes affect the dynamic change in the Köppen climate type in China? Will climate zones move northward owing to climate warming? Will the arid climate zone expand eastward? With the change in climate type, crop planting systems, vegetation distribution, biological communities, and ecosystems will change. Understanding the changes in the Köppen climate types in China will help to formulate measures to adapt to and mitigate these changes to promote sustainable development.

This paper used the monthly temperature and precipitation data from 458 weather stations to explore the Köppen climate type changes during the period of 1964 - 2015 in China. The main purposes of this paper are: (1) to explore the changes in the temperature and precipitation; (2) to analyze the changes in the average Köppen climate type at each station; (3) to investigate the changes in the frequency of annual Köppen climate type at each station. The objective of this paper is to explore Köppen climate change in China, which can provide a basis for political policies such as water resources management, crop system formulation, and land resource management.

\section{DATA AND METHODS}

\subsection{Climate Data}

We obtained the datasets of monthly average temperature and precipitation from more than 800 stations during 1964 - 2015 from the China Meteorological Administration. The climate data has been strictly controlled and inspected by the China Meteorological Administration, and we eliminated the stations with missing data. Finally, 458 weather stations with complete data were used in this study. The weather stations are mainly distributed in the eastern region, while the number of stations in the western region is limited.

\subsection{Köppen Climate Classification}

The Köppen climate classification system creates classifications according to temperature and precipitation data, which are essential for assessing climate change and are available at each weather station. The Köppen-Geiger climate classification criteria used in this study are listed in Table 1. There are five main climate zones in this classification: (A) tropical, (B) arid, (C) temperate, (D) cold, and (E) polar. The arid climate is classified first, and then the tropical, temperate, cold, and polar climates are classified in sequence. Based on the seasonal characteristics of temperature and precipitation, each climate zone was divided into climate subtypes. For the detailed standards of the Köppen climate classification, please refer to the report by Peel et al. (2007).

Notably, as shown in Table 1, some sites satisfy the dry summer climate $(\mathrm{Cs})$ and dry winter climate $(\mathrm{Cw})$ criteria simultaneously. In such a situation, it is necessary to determine whether it is dry in summer or in winter based on the seasonal rainfall. For example, Table 2 showed the records of monthly temperature and precipitation for the Dali station averaged from 1964 to 1989 . More than $70 \%$ of the precipitation for the Dali station occurred in summer, with a $\mathrm{P}_{\text {threshold }}$ of 57.8 (calculated as $2 \times 15.1+28$ ), which was not an arid climate. $\mathrm{T}_{\text {cold }}$ was $8.2^{\circ} \mathrm{C}$, and $\mathrm{T}_{\text {hot }}$ was $20.1^{\circ} \mathrm{C}$, indicating Dali has a temperate climate. $\mathrm{P}_{\text {sdry }}(24.9 \mathrm{~mm})$ was 
Table 1. Description of the Köppen climate type criteria. MAP = mean annual precipitation, $\mathrm{MAT}=$ mean annual temperature, $\mathrm{T}_{\mathrm{hot}}=$ temperature of the hottest month, $\mathrm{T}_{\text {cold }}=$ temperature of the coldest month, $\mathrm{T}_{\text {mon } 10}=$ number of months where the temperature is above $10, \mathrm{P}_{\text {dry }}=$ precipitation of the driest month, $\mathrm{P}_{\text {sdry }}$ $=$ precipitation of the driest month in summer, $\mathrm{P}_{\mathrm{wdry}}=$ precipitation of the driest month in winter, $\mathrm{P}_{\text {swet }}=$ precipitation of the wettest month in summer, $\mathrm{P}_{\mathrm{wwet}}=$ precipitation of the wettest month in winter, $\mathrm{P}_{\text {threshold }}=$ varies according to the following rules (if $70 \%$ of MAP occurs in winter then $\mathrm{P}_{\text {threshold }}=2 \times$ MAT, if $70 \%$ of MAP occurs in summer then $\mathrm{P}_{\text {threshold }}=2 \times$ MAT +28 , otherwise $\mathrm{P}_{\text {threshold }}=2 \times$ MAT +14$)$. Summer (winter) is defined as the warmer (cooler) six-month period of April to September (October to March). The unit for precipitation and temperature is $\mathrm{mm}$ and ${ }^{\circ} \mathrm{C}$, respectively.

\begin{tabular}{|c|c|c|c|c|}
\hline 1st & 2nd & 3rd & Description & Criteria \\
\hline \multirow[t]{4}{*}{ A } & & & Tropical & $\mathrm{T}_{\text {cold }} \geq 18$ \\
\hline & f & & Rainforest & $\mathrm{P}_{\mathrm{dry}} \geq 60$ \\
\hline & $\mathrm{m}$ & & Monsoon & Not (Af) and $P_{d r y} \geq(100-M A P / 25)$ \\
\hline & w & & Savannah & Not $(\mathrm{Af})$ and $\mathrm{P}_{\mathrm{dry}}<(100-\mathrm{MAP} / 25)$ \\
\hline \multirow[t]{5}{*}{$\mathrm{B}$} & & & Arid & MAP $<10 \times \mathrm{P}_{\text {threshold }}$ \\
\hline & $\mathrm{W}$ & & Desert & MAP $<5 \times \mathrm{P}_{\text {threshold }}$ \\
\hline & $S$ & & Steppe & $\mathrm{MAP} \geq 5 \times \mathrm{P}_{\text {threshold }}$ \\
\hline & & $\mathrm{h}$ & Hot & MAT $\geq 18$ \\
\hline & & $\mathrm{k}$ & Cold & MAT $<18$ \\
\hline \multirow[t]{7}{*}{$\mathrm{C}$} & & & Temperate & $\mathrm{T}_{\text {hot }}>10$ and $0<\mathrm{T}_{\text {cold }}<18$ \\
\hline & s & & Dry Summer & $\mathrm{P}_{\text {sdry }}<40$ and $\mathrm{P}_{\text {sdry }}<\mathrm{P}_{\text {wwel }} / 3$ \\
\hline & w & & Dry Winter & $\mathrm{P}_{\mathrm{wdry}}<\mathrm{P}_{\text {swet }} / 10$ \\
\hline & $\mathrm{f}$ & & Without dry season & Not $(\mathrm{Cs})$ or $(\mathrm{Cw})$ \\
\hline & & $\mathrm{a}$ & Hot Summer & $\mathrm{T}_{\text {hot }} \geq 22$ \\
\hline & & $\mathrm{b}$ & Warm Summer & Not (a) and $\mathrm{T}_{\mathrm{mon} 10} \geq 4$ \\
\hline & & $\mathrm{c}$ & Cold Summer & Not $(\mathrm{a}$ or $\mathrm{b})$ and $1 \leq \mathrm{T}_{\operatorname{mon} 10}<4$ \\
\hline \multirow[t]{8}{*}{$\mathrm{D}$} & & & Cold & $\mathrm{T}_{\text {hot }}>10$ and $\mathrm{T}_{\text {cold }} \leq 0$ \\
\hline & s & & Dry Summer & $\mathrm{P}_{\text {sdry }}<40$ and $\mathrm{P}_{\text {sdry }}<\mathrm{P}_{\text {wwel }} / 3$ \\
\hline & w & & Dry Winter & $\mathrm{P}_{\text {wdry }}<\mathrm{P}_{\text {swel }} / 10$ \\
\hline & f & & Without dry season & Not (Ds) or (Dw) \\
\hline & & a & Hot Summer & Thot $\geq 22$ \\
\hline & & $\mathrm{b}$ & Warm Summer & Not (a) and $\mathrm{T}_{\mathrm{mon} 10} \geq 4$ \\
\hline & & c & Cold Summer & Not $(a, b$ or $d)$ \\
\hline & & d & Very Cold Winter & Not $(\mathrm{a}$ or $\mathrm{b})$ and $\mathrm{T}_{\text {cold }}<-38$ \\
\hline \multirow[t]{3}{*}{$\mathrm{E}$} & & & Polar & $\mathrm{T}_{\text {hot }}<10$ \\
\hline & $\mathrm{T}$ & & Tundra & $\mathrm{T}_{\text {hot }}>0$ \\
\hline & $\mathrm{F}$ & & Frost & $\mathrm{T}_{\mathrm{hot}} \leq 0$ \\
\hline
\end{tabular}

Table 2. Monthly precipitation $(\mathrm{mm})$ and average temperature $\left({ }^{\circ} \mathrm{C}\right)$ for the Dali station averaged from 1964 to 1989.

\begin{tabular}{lcccccccccccc}
\hline & Jan & Feb & Mar & Apr & May & Jun & Jul & Aug & Sep & Oct & Nov & Dec \\
\hline Precipitation & 14.9 & 24.0 & 31.5 & 24.9 & 60.3 & 178.6 & 181.7 & 223.3 & 165.5 & 101.5 & 33.9 & 15.9 \\
Temperature & 8.2 & 10.3 & 13.1 & 15.6 & 18.8 & 20.1 & 20.0 & 19.2 & 17.9 & 15.2 & 11.4 & 8.4 \\
\hline
\end{tabular}


less than $40 \mathrm{~mm}$ and below one-third of $\mathrm{P}_{\text {wwet }}(33.8 \mathrm{~mm})$, which indicated that it was a temperate climate, with Cs. At the same time, $\mathrm{P}_{\text {wdry }}(14.9 \mathrm{~mm})$ was less than one-tenth of $\mathrm{P}_{\text {swet }}(22.3 \mathrm{~mm})$. Therefore, the station met both the $\mathrm{Cs}$ and $\mathrm{Cw}$ classification standards. However, the rainfall in summer $(834.3 \mathrm{~mm})$ was greater than that in winter $(221.7 \mathrm{~mm})$. Therefore, the Dali station was determined to be the $\mathrm{Cw}$ climate type. $\mathrm{T}_{\text {hot }}$ was lower than $22^{\circ} \mathrm{C}$, and $\mathrm{T}_{\text {mon }}$ was greater than 4 , indicating that it was a temperate climate with a dry winter and hot summer (Cwa). Similarly, in a cold climate, it can also be required to determine whether the region is dry in summer or in winter.

\subsection{Methods}

In China, solar radiation changed from dimming to brightening during the early 1990s, and the diurnal temperature range changed from a significant downward trend to no significant change simultaneously (Ye et al. 2010; Tang et al. 2011; Shen et al. 2014). Considering the rapid climate change after the 1990s, this study analyzed the changes in Köppen climate types in China by comparing the climate type of each station during two different study periods: 1964 - 1989 and 1990 - 2015. For the climate type of each site in one year, we determined its Köppen climate type based on the climate data of this site in this year. To determine the average climate type of each site during two different study periods, the temperature and precipitation of the station were first averaged over the corresponding years and then classified according to the Köppen climate classification. Therefore, for the average climate type during 1964 1989 (1990 - 2015), each site had only one climate type. For example, it can be seen that Dali station was classified as the Cwa climate type during the period 1964 - 1989 based on the monthly temperature, and precipitation for Dali station averaged over the period 1964 - 1989 (Table 2). The frequency of occurrence of the climate type at each site during 1964 - 1989 (1990 - 2015) was calculated to be the number of years for which that climate type appeared at each site in the 26-year period as a percentage. For example, there was only Dwa climate type in Harbin from 1990 to 2015, so its frequency was $100 \%$ (Fig. 1). For the frequency change of each climate type at each site, we calculated the difference in the frequency of occurrence of each climate type at each site between the periods 1990 - 2015 and 1964 - 1989. The frequency of climate type at each site clearly shows the stations with large inter-annual changes in climate types and stations with almost no inter-annual changes in climate types. As shown in Fig. 1, the frequency changes of BSk, Dwa, and Dwb at the Harbin site were $-8 \%,+35 \%$, and (a)


(b)
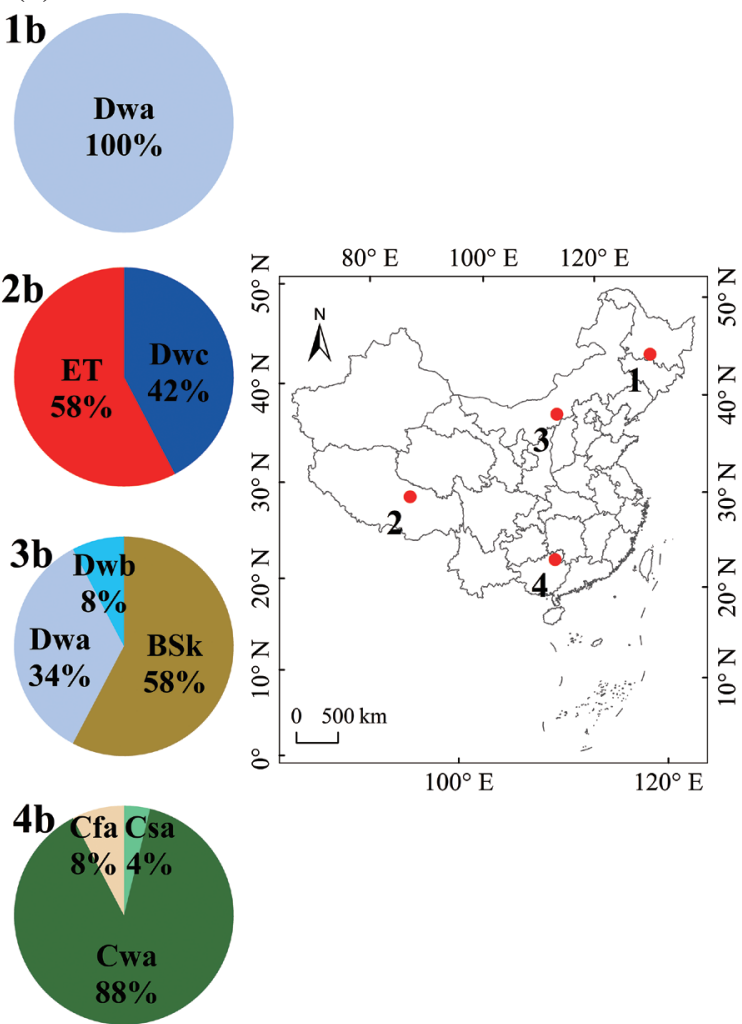

Fig. 1. Examples of frequencies of Köppen climate type for Harbin (1), Naqu (2), Hohhot (3), and Guilin (4) for the periods of 1964 - 1989 (a) and 1990 - 2015 (b). See Table 1 for the details of the Köppen climate types. 
$-27 \%$, respectively. To assess the causes of climate change, we analyzed the spatial changes in temperature and precipitation from 1964 to 2015.

\section{RESULTS}

\subsection{Changes in Temperature and Precipitation}

The spatial variations of temperature and precipitation in China for the period of 1964 - 2015 were shown in Figs. 2 and 3.

The changes in annual temperature (Fig. 2a) showed that most regions in China were warming, but the warming rate was inconsistent among regions. Strong warming $\left(>0.4^{\circ} \mathrm{C}\right.$ decade $\left.^{-1}\right)$ appeared in North China, the northern regions of Northeast China, and the central regions of the Tibetan Plateau. Moderate warming $\left(0.2-0.4^{\circ} \mathrm{C}\right.$ decade $\left.^{-1}\right)$ appeared in Northeast China, Northwest China, and East China. The weakest warming $\left(<0.2^{\circ} \mathrm{C}\right.$ decade $\left.^{-1}\right)$ occurred in Southwest China, Central China, and South China. The changes in winter temperature (October to March, Fig. 2b) were similar to those in the annual temperature, while the warming degree in winter temperature was stronger. The rate of temperature increase at some sites exceeded $0.8^{\circ} \mathrm{C}$ decade $^{-1}$. In summer (April to September, Fig. 2c), the spatial distribution of temperature changes was similar to that of the annual temperature, but the warming was weaker. In eastern China, the warming rate in most areas south of $35^{\circ} \mathrm{N}$ was lower than $0.2^{\circ} \mathrm{C}$ decade $^{-1}$. Although the warming ranges differed in winter, summer, and annually, the results suggest that the temperature in most parts of China increased.

The changes in annual precipitation were more heterogeneous (Fig. 3a). Precipitation in the northern part of Northeast China, the Tibetan Plateau, and East China increased, and the increase in East China (> $\left.20 \mathrm{~mm} \mathrm{decade}^{-1}\right)$ was largest. Reduced precipitation occurred in North China, Southwest China, and South China, and the decline in Southwest China $\left(<-20 \mathrm{~mm} \mathrm{decade}^{-1}\right)$ was largest. In winter (Fig. 3b), increasing precipitation appeared in Northeast China, the Tibetan Plateau, East China, Central China, and South China. Precipitation in North China, Southwest China, and the southern coastal area decreased. The variation range of winter precipitation was less than that of the annual precipitation. In summer (Fig. 3c), the spatial distribution of precipitation changes was similar to that of the annual precipitation, but the increase in East China was lower.

\subsection{Changes in Average Types}

The average Köppen climate types for each station in China calculated for the periods of 1964 - 1989 and 1990 2015 were shown in Fig. 4. The two maps showed that there were 12 climate types, and tropical monsoon (Am), tropical savannah (Aw), and temperate climate with no dry season and warm summer $(\mathrm{Cfb})$ had the fewest stations. Am and
Aw were mainly distributed in the southern part of Hainan, while $\mathrm{Cfb}$ was scattered in the southern region of China.

The arid climate included cold desert (BWk) and cold steppe (BSk). The BSk climate type, which was mainly distributed in the Inner Mongolia Plateau and the Loess Plateau, was represented at 52 and 63 stations for the two periods, respectively. BWk was dominant in the northwest of the study area, including approximately $4 \%$ of stations for 1964 - 1989 and 1990 - 2015. The temperate climate type included nearly $46 \%$ of the stations, among which a temperate climate with no dry season and hot summer (Cfa) was the dominant climate type. The Cfa climate type was found in the southeast. A temperate climate with dry winter and hot summer (Cwa) was distributed in Jiangsu, Anhui, Henan, Hubei, Sichuan, Guizhou, Yunnan, Guangxi, and Guangzhou. As the altitude increases, Cwa turned into Cwb, especially in the Yunnan-Guizhou Plateau. In highlatitude and high-altitude areas, more than $30 \%$ of the stations were located in cold climates. A cold climate with dry winter and hot summer (Dwa) was distributed in the north of the Qinling-Huaihe Line and east of the Hu Line. A cold climate with dry winter and warm summer (Dwb) was distributed in the Lesser Khingan Mountains, Changbai Mountain, Loess Plateau, and Tibetan Plateau. A cold climate with dry winter and cold summer (Dwc) was located in the Greater Khingan Range and Tibetan Plateau. The polar climate type included only the tundra climate (ET), corresponding to the region with the lowest temperature in the hottest month on the Tibetan Plateau.

Changes in average climate types for each station over the two periods were shown in Table 3 and Fig. 5. It showed that the average climate types of 73 stations changed, but most of them had maintained a balanced state. For example, 16 stations had changed to Cwa while 18 had left. The evolution mainly involved the BSk, Cfa, and Dwb. Both BSk (+11 stations) and Cfa (+11 stations) maintained a dominant occurrence. The BSK occurrence range moved approximately $2^{\circ}$ to the southeast in the Loess Plateau and expanded about $1^{\circ}$ to the northeast in Northeast China. The Cfa occurrence expanded approximately $1^{\circ}$ to the north in East China and moved approximately $1.5^{\circ}$ to the south in the coastal areas of Southern China. Dwb (-12 stations) retreated approximately $1.5^{\circ}$ to the northeast of the Northeast Plain, which transitioned into Dwa. In addition, Cwa expanded approximately $0.5^{\circ}$ to the north in the Qinling-Huaihe, and ET transitioned to Dwc in the high-altitude areas.

\subsection{Frequency Changes of Annual Climate Type}

The frequency distributions of climate types at 458 stations per year during the two periods were shown in Fig. 6. The distribution characteristics were similar to those of the above-mentioned average types. The biggest difference occurred in the southeast, where Cwa was dominant 


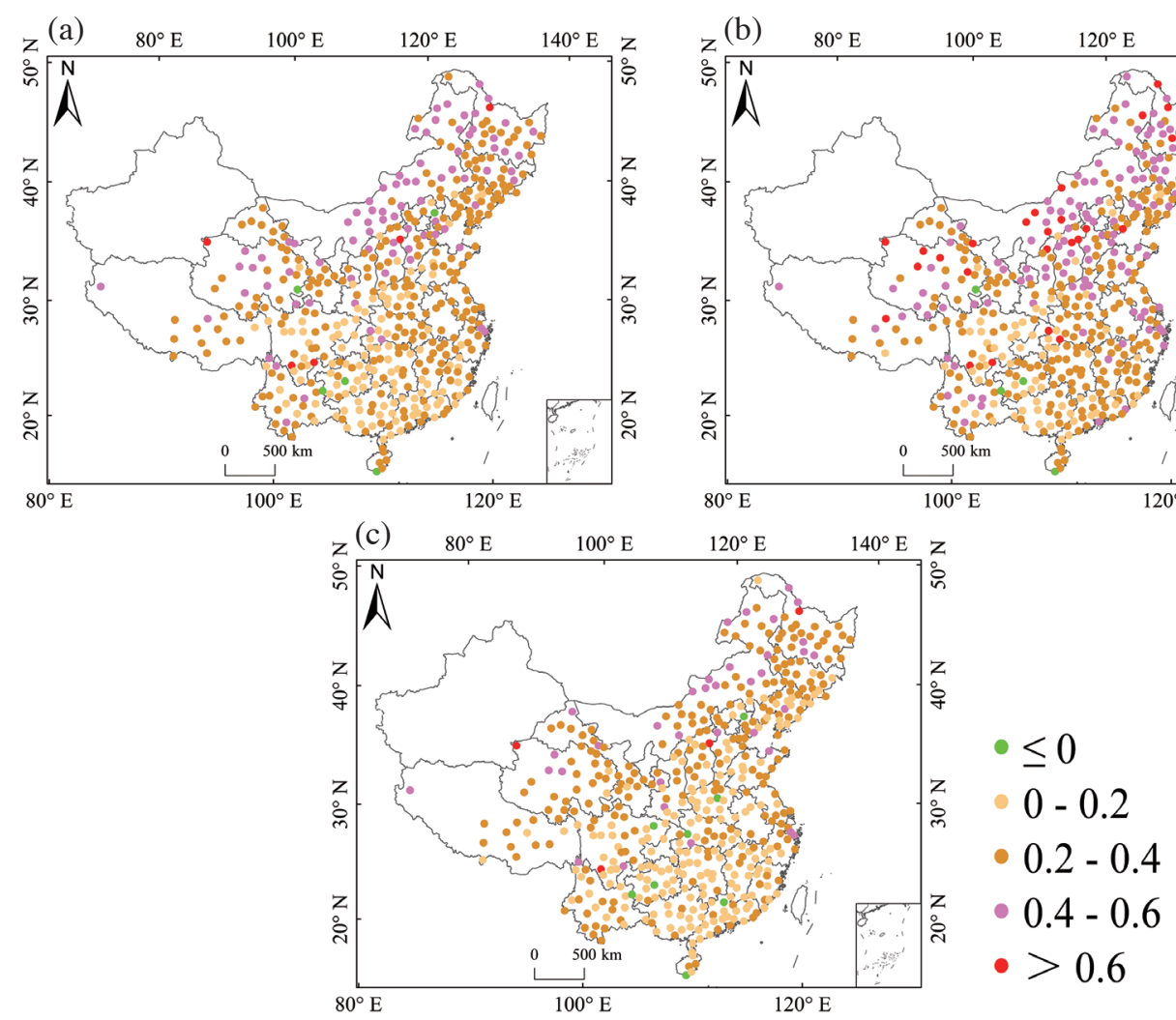

Fig. 2. Spatial distribution of temporal trends in annual (a), winter (October to March) (b), and summer (April to September) (c) temperatures $\left({ }^{\circ} \mathrm{C}\right.$ decade $^{-1}$ ).

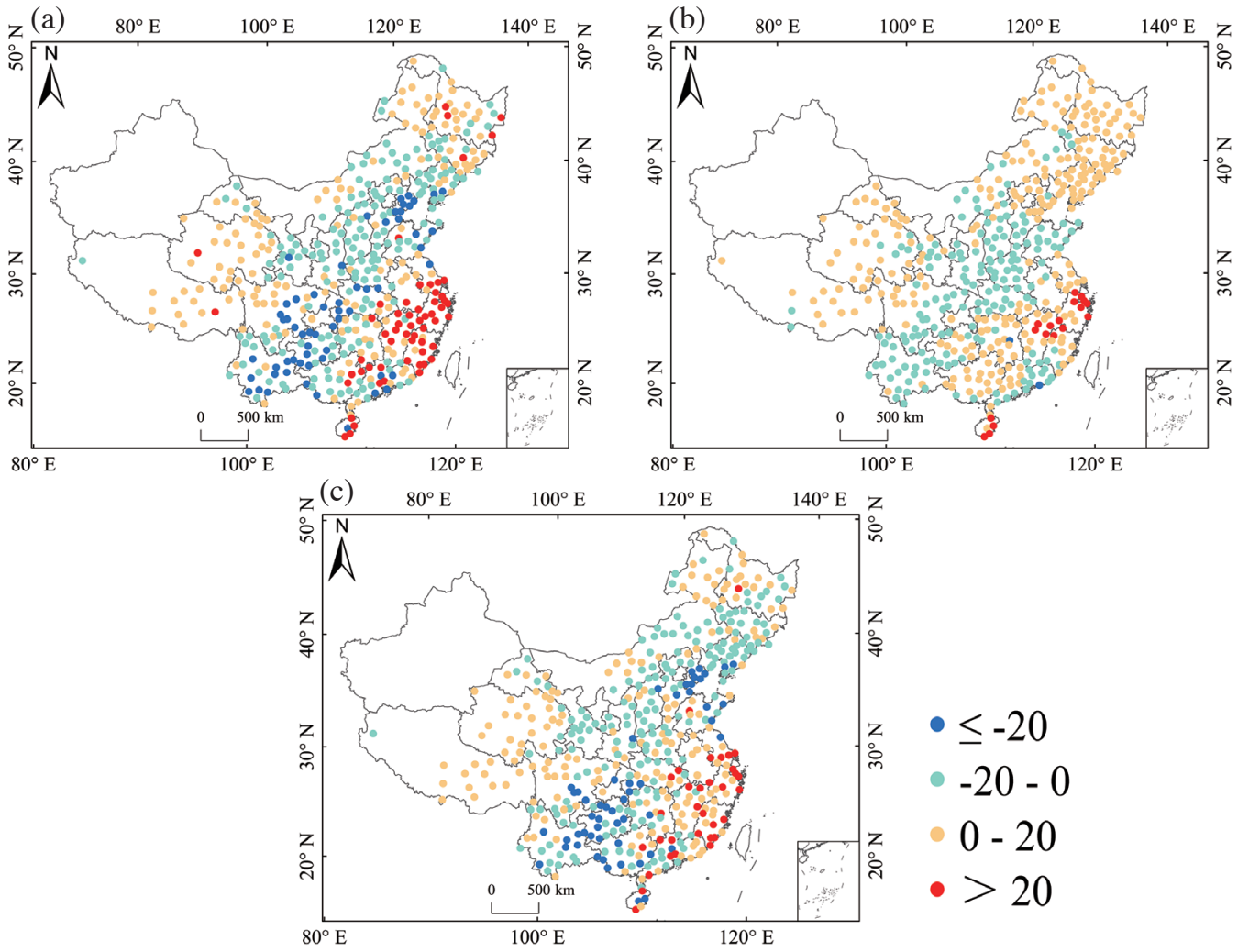

Fig. 3. Spatial distribution of temporal trends in annual (a), winter (October to March) (b), and summer (April to September) (c) total precipitation $\left(\mathrm{mm} \mathrm{decade}^{-1}\right)$. 


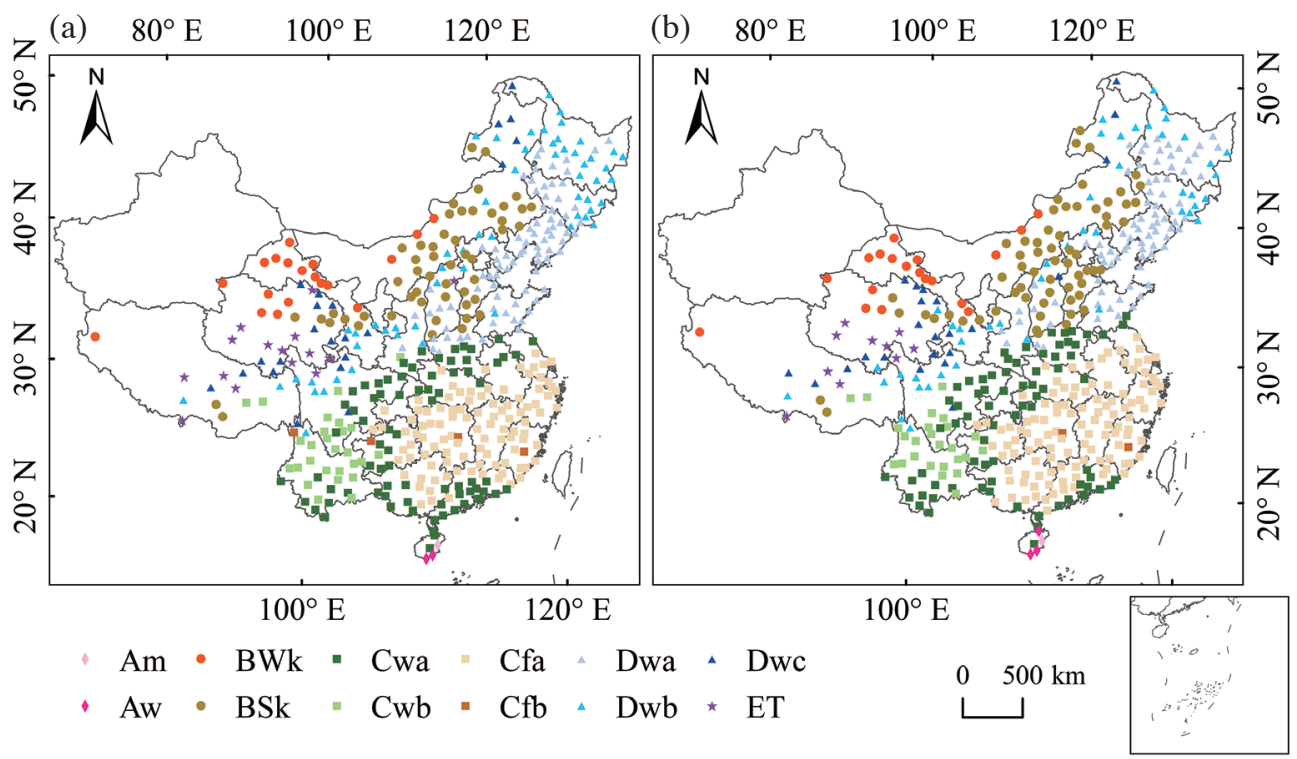

Fig. 4. Average Köppen climate types in China calculated for the periods of 1964 - 1989 (a) and 1990 - 2015 (b). See Table 1 for the details of the Köppen climate types.

Table 3. Number of weather stations that the average Köppen type has changed between the periods 1964 - 1989 and 1990 - 2015. Each cell in the table gives the category change between 1964 - 1989 (horizontal axis) and 1990 2015 (vertical axis); for example, one stations (in bold font) have changed from BWk type to BSk type. See Table 1 for the details of the Köppen climate types.

\begin{tabular}{|c|c|c|c|c|c|c|c|c|c|c|c|c|c|}
\hline Climate types & Am & Aw & BWk & BSk & Cwa & Cwb & Cfa & $\mathbf{C f b}$ & Dwa & Dwb & Dwc & ET & Total \\
\hline $\mathrm{Am}$ & & & & & & & & & & & & & 0 \\
\hline Aw & & & & & & & & & & & & & 0 \\
\hline BWk & & & & 1 & & & & & & & & & -1 \\
\hline BSk & & & 1 & & & & & & & 1 & & & -2 \\
\hline Cwa & & 1 & & & & & 17 & & & & & & -18 \\
\hline Cwb & & & & & 4 & & & & & & & & -4 \\
\hline $\mathrm{Cfa}$ & & & & & 6 & & & & & & & & -6 \\
\hline $\mathrm{Cfb}$ & & & & & & 2 & & & & & & & -2 \\
\hline Dwa & & & & 8 & 6 & & & & & & & & -14 \\
\hline Dwb & & & & 4 & & & & & 13 & & & & -17 \\
\hline Dwc & & & & & & & & & & 4 & & & -4 \\
\hline ET & & & & & & & & & & & 5 & & -5 \\
\hline Total & 0 & +1 & +1 & +13 & +16 & +2 & +17 & 0 & +13 & +5 & +5 & 0 & 73 \\
\hline
\end{tabular}




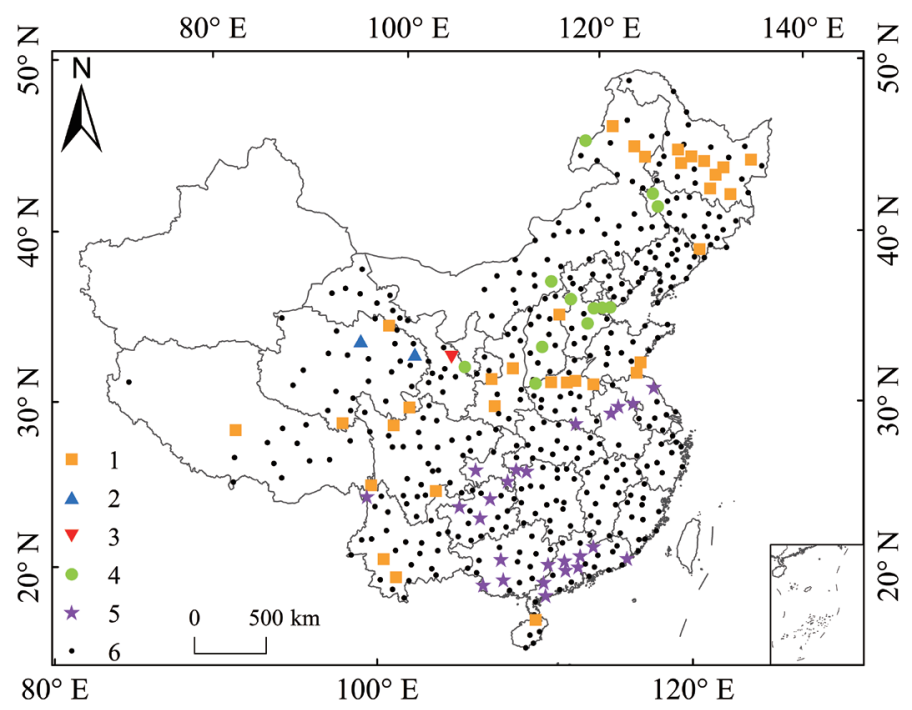

Fig. 5. Map synthesis of stations that the Köppen climate types have changed between 1964 - 1989 and 1990 - 2015. (1) Conversion towards a warmer climate type; (2) conversion towards a wetter climate; (3) conversion towards a drier climate; (4) conversion towards a more arid climate; (5) other type of conversion ( $\mathrm{Cwa} \rightarrow \mathrm{Cfa}, \mathrm{Cfa} \rightarrow \mathrm{Cwa}$, and $\mathrm{Cfb} \rightarrow \mathrm{Cwb})$; (6) no change.

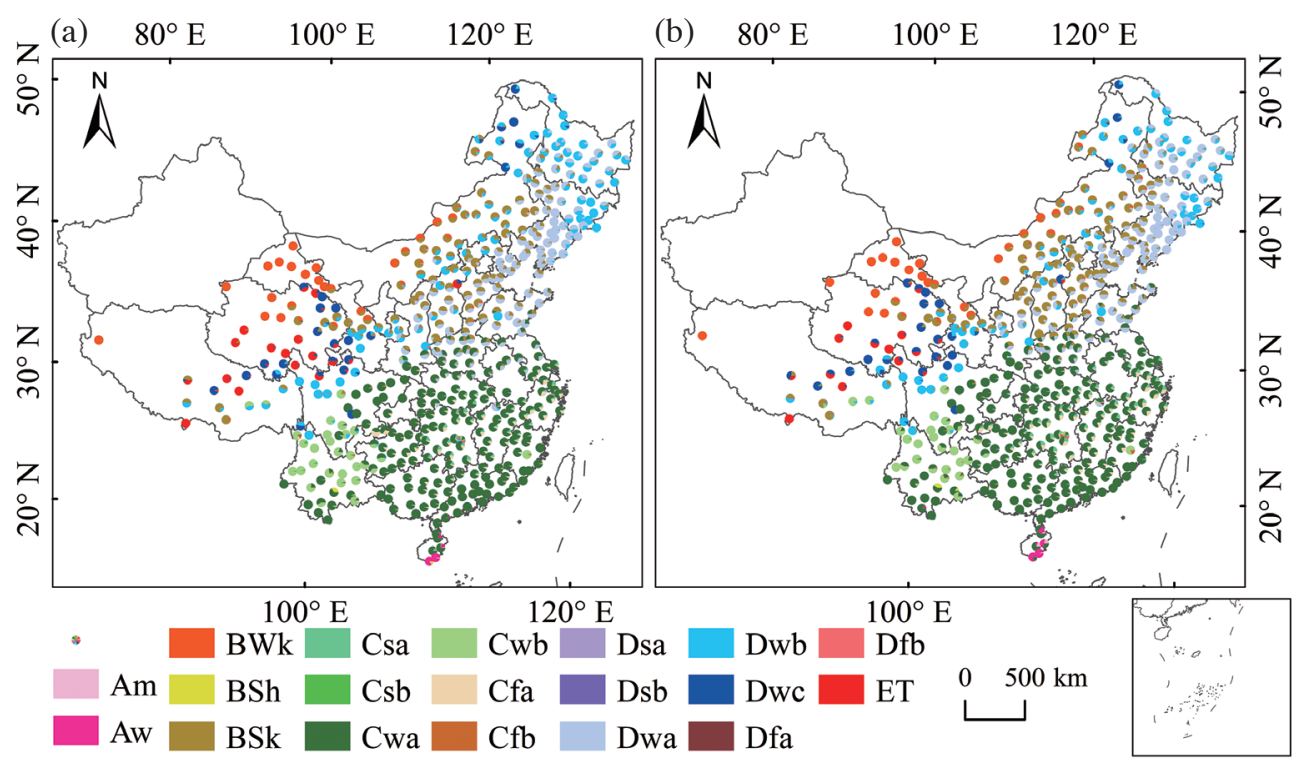

Fig. 6. Frequency of Köppen climate type at each site for the periods of 1964 - 1989 (a) and 1990 -2015 (b). See Table 1 for the details of the Köppen climate types. 
in the frequency distribution maps and Cfa prevailed in the average climate type distribution maps. In addition, some climate types were not mentioned above. In these climate types, hot steppe (BSh), temperate climate with dry summer and warm summer (Csb), and cold climates with dry summer (Dsa and Dsb), and no dry season (Dfa and Dfb) were particularly rare. A temperate climate with dry summer and hot summer (Csa) (about 2\%) was located in the southeast and was replaced by $\mathrm{Cfa}$ as the average climate type. Table 4 showed the frequency changes for each climate type. Am, Aw, BWk, BSk, temperate climates with hot summer (Csa, Cwa, and Cfa), and Dwc increased, with the most significant increase in BSk. Temperate and cold climates with warm summer (Csb, Cwb, and Dwb), cold climates with no dry season and hot summer (Dfa), and ET decreased, and the most significant decrease was in Dwb.

The frequency variation of the major climate types was shown in Fig. 7. The BWk and BSk increased significantly. The former was mainly concentrated in the Inner Mongolia Plateau, while the latter was mainly distributed in the Loess Plateau, Northeast Plain, and northeast of the Inner Mongolia Plateau. In the southeast, the Csa climate type increased at most stations. A decrease in Cwa type was found in South China, East China, and Central China, while an increase in Cwa type was distributed in the Huang Huai Plain and Yunnan-Guizhou Plateau, where the Cwb type occurrence decreased. The increase in frequency of Cfa was located near the coast, and a decrease was distributed to the west and north. The increase in Dwa was mainly concentrated at high latitudes and altitudes, and most other areas decreased. The Dwb type decreased significantly and was distributed in Northeast China and North China. In the Tibetan Plateau, Dwc was characterized by an increase, whereas ET decreased.

\section{DISCUSSION}

This study used Köppen-Geiger climate classification to analyze climate distribution and change based on the 458 meteorological stations in China from 1964 to 2015. The Köppen-Geiger climate classification combined temperature and precipitation data and classified the weather stations according to their seasonal distribution characteristics. We found that the temperature in most parts of China has increased, with a larger increase in Northern China. The variation in precipitation was diverse, and stations with increased precipitation in winter were dominant. In the areas of Southeastern China, Northeast China, and the Tibetan Plateau, the rate of change in winter precipitation was between 0 and 20 $\mathrm{mm} / 10 \mathrm{a}$. According to the Köppen-Geiger climate classification, the arid climate is mainly distributed in the northern part of China. The desert climate was concentrated in the northwest, with the steppe climate surrounding the desert climate. These findings were consistent with those of previ- ous studies on the distribution of drought. Liu et al. (2017) found that drought was mainly distributed in northern China based on the Microwave Temperature Vegetation Drought Index; Wei et al. (2020) indicated that drought in China had gradually become more severe from southeast to northwest. This is mainly because the northwest is located inland, far from the sea, and precipitation gradually decreases from southeast to northwest. We also found that tropical, temperate, and cold climates were distributed in sequence from south to north in eastern China, and the polar climate was concentrated in the Tibetan Plateau. This was consistent with the findings of Li and Zha (2018), who found that the temperature showed a decreasing trend from south to north in the eastern part of China, while gradually decreasing with the increase in altitude in the Tibetan Plateau. Similar to previous studies on the distribution characteristics of drought and temperature, our study accurately showed the distribution characteristics of the climate in China.

In our study, climate change was mainly reflected in the eastward and southward expansion of arid climate and northward movement of climatic zones, which was consistent with the trend of global drying and warming (Zarch et al. 2017). The expansion of the arid climate was mainly reflected in the steppe climate, which mainly occurred in the North China Plain and the eastern part of the Inner Mongolia Plateau. The decreased precipitation could account for the expansion of the arid climate zone (Fig. 3). This expansion of arid climate was consistent with the research of Kim et al. (2008), who indicated that the arid climate in North China revealed expansion characteristics during 1951 - 2000. Additionally, Zou et al. (2005) reported that the area of drought increased significantly, and the intensity and duration of drought increased in northern China, and $\mathrm{Ma}$ and $\mathrm{Fu}$ (2006) demonstrated that the frequency of extreme droughts in the eastern part of Northwest China, the central part of North China, and Northeast China had increased significantly since the 1980s. Chen and Sun (2015) showed that drought in Northern China has become increasingly serious and frequent since the 1990s. In summary, the expansion of the arid zone may be related to rising temperatures, decreasing precipitation, and increasing evaporation ( $\mathrm{Yu}$ et al. 2004; Vicente-Serrano et al. 2015; Duan et al. 2020).

Another significant observation of our study was climate warming, including conversion from ET to Dwc, Dwb to Dwa, and Dwa to Cwa. Chan et al. (2016) showed that climate change in China was mainly concentrated in several regions over the past few decades, which is consistent with our results. In Northeast China, warmer summer replaced colder summer (Dwa replaced Dwb, and Dwb replaced Dwc). In the Tibetan Plateau, ET was replaced by Dwc, and Dwa was replaced by Cwa over the Qinling-Huaihe. The main reason for these changes could be the increase in temperature (Fig. 2). Many studies have shown that the temperature in China has increased (Xu et al. 2019; Yan et 
Table 4. Frequency differences (\%) of Köppen climate type in China between the periods $1990-2015$ and 1964 - 1989. See Table 1 for the details of the Köppen climate types.

\begin{tabular}{cccc}
\hline Climate type & Frequency of 1964 - 1989 & Frequency of 1990 - 2015 & Frequency change \\
\hline Am & 0.0 & 0.1 & 0.1 \\
Aw & 0.5 & 0.6 & 0.1 \\
BWk & 4.7 & 5.0 & 0.3 \\
BSh & 0.1 & 0.1 & 0.0 \\
BSk & 13.3 & 15.1 & 1.8 \\
Csa & 1.5 & 2.1 & 0.6 \\
Csb & 0.1 & 0.0 & -0.1 \\
Cwa & 34.2 & 34.9 & 0.7 \\
Cwb & 5.3 & 5.0 & -0.3 \\
Cfa & 2.5 & 2.8 & 0.3 \\
Cfb & 0.1 & 0.1 & 0.0 \\
Dsa & 0.0 & 0.0 & 0.0 \\
Dsb & 0.0 & 0.0 & 0.0 \\
Dwa & 17.0 & 17.0 & 0.0 \\
Dwb & 13.0 & 10.4 & -2.6 \\
Dwc & 4.5 & 4.6 & 0.1 \\
Dfa & 0.1 & 0.0 & -0.1 \\
Dfb & 0.1 & 0.1 & 0.0 \\
ET & 3.0 & 2.1 & -0.9 \\
\hline
\end{tabular}
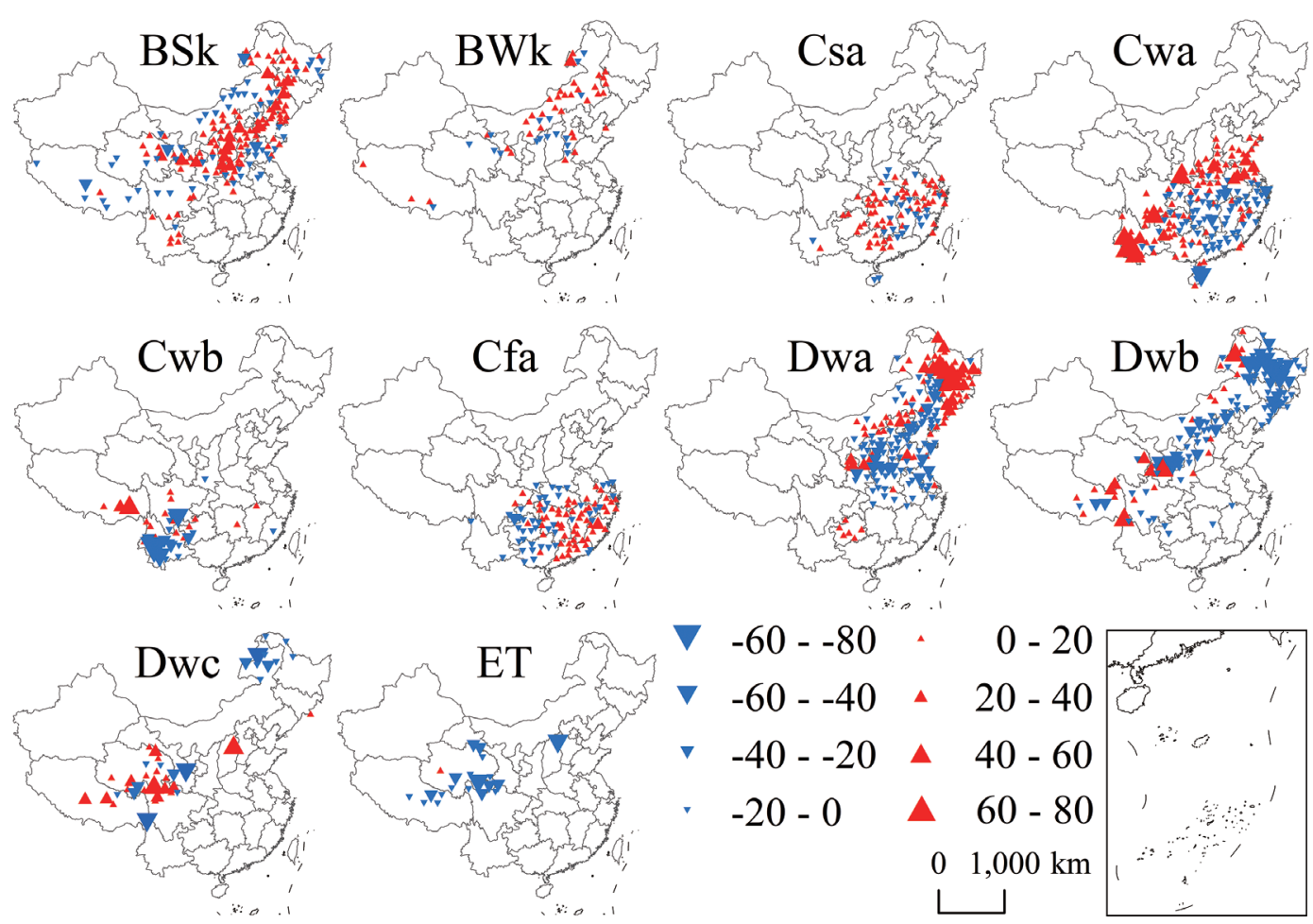

Fig. 7. Frequency differences (\%) of Köppen climate type at each site in China between the periods 1990 - 2015 and 1964 - 1989. See Table 1 for the details of the Köppen climate types. 
al. 2020), and the hot extreme index increased more significantly in Northern China than in Southern China (Chen et al. 2018; Shi et al. 2018). In the southeastern coastal areas of China, increased winter precipitation was the main cause of Cwa conversion to Cfa.

We found that drying and warming are the main characteristics of climate change in China over the past decades. Aridity is a natural disaster with the highest frequency and the most extensive impact worldwide, which damages the economy, ecology, and agriculture (Westerling et al. 2006; Feng et al. 2016; Jiang et al. 2019). An arid climate could reduce agricultural production and cause huge economic losses (Zhang and Jia 2013; Liu et al. 2018). Therefore, we should take appropriate management measures, such as the implementation of South-to-North water transfer schemes, the introduction of drought-tolerant varieties, adjustment of irrigation technology, and recycling of wastewater, in arid areas to alleviate the adverse effects of an arid climate (Challinor et al. 2014; Zhao et al. 2015; Qu et al. 2020). Under the influence of climate warming, we found that climate boundaries shifted northward in China. On the one hand, climate warming can reduce the frequency of low-temperature damage from freezing, increase crop yield, and promote agricultural development (Bai et al. 2020; Yuan et al. 2020). On the other hand, climate warming may promote the reproduction of pests and increase the risk of pests (Bajwa et al. 2020). Therefore, some heat-resistant and pest-resistant varieties should be introduced to these warming regions. Agriculture is the basis of national economic development, and understanding the change in climate is of great significance for the development of agricultural production in China.

Although this study provides a comprehensive assessment of variations of the Köppen climate types in China, some limitations remain. Firstly, there are a limited number of stations in the Tibetan Plateau and northwestern China. Therefore, our results from the weather data of these stations do not accurately reflect the actual climate conditions in China. Secondly, the highland climatic type has been isolated in the current Köppen climate classification, which may cause some inaccuracy in the climate classification of the Tibetan Plateau. In addition, the Köppen climate classification used in this study may have some shortcomings, as it only focuses on an analysis of the numerical value of the climate elements and ignores the climate formation processes. For example, we found that the temperate climate type was distributed in the area south of $20^{\circ} \mathrm{N}$. To analyze the climate in China more accurately, it is necessary to further verify the local climate conditions in different Köppen climate types in China and modify the corresponding parameters of the Köppen climate classification to make it more suited to China.

\section{CONCLUSION}

Based on the temperature and precipitation data from
458 weather stations from 1964 to 2015 , this study analyzed changes in the Köppen climate type in China. We observed changes in temperature and precipitation, as well as average climate type and frequency in the annual climate type at each station in the past few decades. The temperature increased in most areas, with a larger increase in Northern China. The variation in precipitation was diverse, and there were more stations with increased precipitation in winter. The changes in temperature and precipitation caused changes to the climate type. Changes in the Köppen climate type have significant regional characteristics. BSk extended to the southeast in Northern China; cold climate with dry winter (Dwa, Dwb, and Dwc) extended northward in Northeast China; Cwa extended northward in East China and Central China; Dwc and ET moved to high altitudes in the Tibetan Plateau; Cwa changed to Cfa in the southeast coastal areas of China. Owing to the increase in temperature, the climate types of Cwa, Dwa, Dwb, and Dwc moved northward. Moreover, the decreased precipitation might account for the eastward and southward expansion of arid climate type of BSk. As climate change has an important impact on agricultural production and human life, it warrants increased attention in China, especially in climate-sensitive regions.

Acknowledgements This work was supported by the National Key Research and Development Program of China (2019YFC0409101); National Natural Science Foundation of China (41971065); Youth Innovation Promotion Association, CAS (2019235); Key Research Program of Frontier Sciences, Chinese Academy of Sciences (ZDBS-LY-7019). The temperature and precipitation data were obtained from China Meteorological Data Service Centre of China Meteorological Administration (http://data.cma.cn/en). We thank Dr. Baba Diabate for his support in revising English language.

\section{REFERENCES}

Alvares, C. A., J. L. Stape, P. C. Sentelhas, J. L. de Moraes Gonçalves, and G. Sparovek, 2013: Köppen's climate classification map for Brazil. Meteorol. Z., 22, 711728, doi: 10.1127/0941-2948/2013/0507. [Link]

Bai, Y., C. Guo, A. A. Degen, A. A. Ahmad, W. Wang, T. Zhang, W. Li, L. Ma, M. Huang, H. Zeng, L. Qi, R. Long, and Z. Shang, 2020: Climate warming benefits alpine vegetation growth in Three-River Headwater Region, China. Sci. Total Environ., 742, 140574, doi: 10.1016/j.scitotenv.2020.140574. [Link]

Bajwa, A. A., M. Farooq, A. M. Al-Sadi, A. Nawaz, K. Jabran, and K. H. M. Siddique, 2020: Impact of climate change on biology and management of wheat pests. Crop Prot., 137, 105304, doi: 10.1016/j. cropro.2020.105304. [Link]

Baker, B., H. Diaz, W. Hargrove, and F. Hoffman, 2010: Use of the Köppen-Trewartha climate classification 
to evaluate climatic refugia in statistically derived ecoregions for the People's Republic of China. Clim. Change, 98, 113-131, doi: 10.1007/s10584-009-96222. [Link]

Belda, M., E. Holtanová, T. Halenka, and J. Kalvová, 2014: Climate classification revisited: From Köppen to Trewartha. Clim. Res., 59, 1-13, doi: 10.3354/cr01204. [Link]

Challinor, A. J., J. Watson, D. B. Lobell, S. M. Howden, D. R. Smith, and N. Chhetri, 2014: A meta-analysis of crop yield under climate change and adaptation. Nat. Clim. Change, 4, 287-291, doi: 10.1038/NCLIMATE2153. [Link]

Chan, D., Q. Wu, G. Jiang, and X. Dai, 2016: Projected shifts in Köppen climate zones over China and their temporal evolution in CMIP5 multi-model simulations. Adv. Atmos. Sci., 33, 283-293, doi: 10.1007/ s00376-015-5077-8. [Link]

Chen, H. and J. Sun, 2015: Changes in Drought Characteristics over China Using the Standardized Precipitation Evapotranspiration Index. J. Clim., 28, 5430-5447, doi: 10.1175/JCLI-D-14-00707.1. [Link]

Chen, Y. D., J. Li, Q. Zhang, and X. Gu, 2018: Projected changes in seasonal temperature extremes across China from 2017 to 2100 based on statistical downscaling. Global Planet. Change, 166, 30-40, doi: 10.1016/j. gloplacha.2018.04.002. [Link]

Duan, K., J. Guo, T. Hu, X. Wang, and Y. Mei, 2020: Assessing the Roles of Terrestrial Stilling and Solar Dimming in Land Surface Drying/Wetting across China. Water, 12, 1996, doi: 10.3390/w12071996. [Link]

Dubreuil, V., K. P. Fante, O. Planchon, and J. L. Sant'Anna Neto, 2019: Climate change evidence in Brazil from Köppen's climate annual types frequency. Int. J. Climatol., 39, 1446-1456, doi: 10.1002/joc.5893. [Link]

Feng, S., C.-H. Ho, Q. Hu, R. J. Oglesby, S.-J. Jeong, and B.-M. Kim, 2012: Evaluating observed and projected future climate changes for the Arctic using the Köppen-Trewartha climate classification. Clim. Dyn., 38, 1359-1373, doi: 10.1007/s00382-011-1020-6. [Link]

Feng, X., B. Fu, S. Piao, S. Wang, P. Ciais, Z. Zeng, Y. Lü, Y. Zeng, Y. Li, X. Jiang, and B. Wu, 2016: Revegetation in China's Loess Plateau is approaching sustainable water resource limits. Nat. Clim. Change, 6, 10191022, doi: 10.1038/NCLIMATE3092. [Link]

Foley, J. A., R. DeFries, G. P. Asner, C. Barford, G. Bonan, S. R. Carpenter, F. S. Chapin, M. T. Coe, G. C. Daily, H. K. Gibbs, J. H. Helkowski, T. Holloway, E. A. Howard, C. J. Kucharik, C. Monfreda, J. A. Patz, I. C. Prentice, N. Ramankutty, and P. K. Snyder, 2005: Global Consequences of Land Use. Science, 309, 570574, doi: 10.1126/science.1111772. [Link]

Jiang, L., G. Jiapaer, A. Bao, A. Kurban, H. Guo, G. Zheng, and P. De Maeyer, 2019: Monitoring the long-term de- sertification process and assessing the relative roles of its drivers in Central Asia. Ecol. Indic., 104, 195-208, doi: 10.1016/j.ecolind.2019.04.067. [Link]

Kim, H.-J., B. Wang, Q. Ding, and I.-U. Chung, 2008: Changes in Arid Climate over North China Detected by the Köppen Climate Classification. J. Meteorol. Soc. Jpn., 86, 981-990, doi: 10.2151/jmsj.86.981. [Link]

Kottek, M., J. Grieser, C. Beck, B. Rudolf, and F. Rubel, 2006: World Map of the Köppen-Geiger climate classification updated. Meteorol. Z., 15, 259-263, doi: 10.1127/0941-2948/2006/0130. [Link]

Li, L. and Y. Zha, 2018: Mapping relative humidity, average and extreme temperature in hot summer over China. Sci. Total Environ., 615, 875-881, doi: 10.1016/j. scitotenv.2017.10.022. [Link]

Li, X., J. Sardans, L. Hou, M. Liu, C. Xu, and J. Peñuelas, 2020: Climatic temperature controls the geographical patterns of coastal marshes greenhouse gases emissions over China. J. Hydrol., 590, 125378, doi: 10.1016/j. jhydrol.2020.125378. [Link]

Liu, H., B. Huang, and C. Yang, 2020: Assessing the coordination between economic growth and urban climate change in China from 2000 to 2015. Sci. Total Environ., 732, 139283, doi: 10.1016/j.scitotenv.2020.139283. [Link]

Liu, L., J. Liao, X. Chen, G. Zhou, Y. Su, Z. Xiang, Z. Wang, X. Liu, Y. Li, J. Wu, X. Xiong, and H. Shao, 2017: The Microwave Temperature Vegetation Drought Index (MTVDI) based on AMSR-E brightness temperatures for long-term drought assessment across China (2003-2010). Remote Sens. Environ., 199, 302-320, doi: 10.1016/j.rse.2017.07.012. [Link]

Liu, W., W. H. Lim, F. Sun, D. Mitchell, H. Wang, D. Chen, I. Bethke, H. Shiogama, and E. Fischer, 2018: Global Freshwater Availability Below Normal Conditions and Population Impact Under 1.5 and $2^{\circ} \mathrm{C}$ Stabilization Scenarios. Geophys. Res. Lett., 45, 9803-9813, doi: 10.1029/2018GL078789. [Link]

Ma, Z. and C. Fu, 2006: Some evidence of drying trend over northern China from 1951 to 2004. Chin. Sci. Bull., 51, 2913-2925, doi: 10.1007/s11434-006-2159-0. [Link]

McMahon, T. A., M. C. Peel, and D. J. Karoly, 2015: Assessment of precipitation and temperature data from CMIP3 global climate models for hydrologic simulation. Hydrol. Earth Syst. Sci., 19, 361-377, doi: 10.5194/hess-19-361-2015. [Link]

Peel, M. C., B. L. Finlayson, and T. A. McMahon, 2007: Updated world map of the Köppen-Geiger climate classification. Hydrol. Earth Syst. Sci., 11, 1633-1644, doi: 10.5194/hess-11-1633-2007. [Link]

Pražnikar, J., 2017: Particulate matter time-series and Köppen-Geiger climate classes in North America and Europe. Atmos. Environ., 150, 136-145, doi: 10.1016/j. atmosenv.2016.11.056. [Link] 
Qu, X., Y. Chen, H. Liu, W. Xia, Y. Lu, D.-D. Gang, and L.-S. Lin, 2020: A holistic assessment of water quality condition and spatiotemporal patterns in impounded lakes along the eastern route of China's South-to-North water diversion project. Water Res., 185, 116275, doi: 10.1016/j.watres.2020.116275. [Link]

Rajaud, A. and N. de Noblet-Ducoudré, 2017: Tropical semi-arid regions expanding over temperate latitudes under climate change. Clim. Change, 144, 703-719, doi: 10.1007/s10584-017-2052-7. [Link]

Rubel, F., K. Brugger, K. Haslinger, and I. Auer, 2017: The climate of the European Alps: Shift of very high resolution Köppen-Geiger climate zones 1800-2100. Meteorol. Z., 26, 115-125, doi: 10.1127/metz/2016/0816. [Link]

Shen, X., B. Liu, G. Li, Z. Wu, Y. Jin, P. Yu, and D. Zhou, 2014: Spatiotemporal change of diurnal temperature range and its relationship with sunshine duration and precipitation in China. J. Geophys. Res., 119, 1316313179, doi: 10.1002/2014JD022326. [Link]

Shen, X., B. Liu, M. Jiang, and X. Lu, 2020: Marshland loss warms local land surface temperature in China. Geophys. Res. Lett., 47, e2020GL087648, doi: 10.1029/2020GL087648. [Link]

Shen, X., M. Jiang, X. Lu, X. Liu, B. Liu, J. Zhang, X. Wang, S. Tong, G. Lei, S. Wang, C. Tong, H. Fan, K. Tian, X. Wang, Y. Hu, Y. Xie, M. Ma, S. Zhang, C. Cao, and Z. Wang, 2021a: Aboveground biomass and its spatial distribution pattern of herbaceous marsh vegetation in China. Sci. China Earth Sci., 64, 11151125, doi: 10.1007/s11430-020-9778-7. [Link]

Shen, X., B. Liu, M. Jiang, Y. Wang, L. Wang, J. Zhang, and X. Lu, 2021b: Spatiotemporal change of marsh vegetation and its response to climate change in China from 2000 to 2019. J. Geophys. Res., 126, e2020JG006154, doi: 10.1029/2020JG006154. [Link]

Shi, J., L. Cui, K. Wen, Z. Tian, P. Wei, and B. Zhang, 2018: Trends in the consecutive days of temperature and precipitation extremes in China during 19612015. Environ. Res., 161, 381-391, doi: 10.1016/j.envres.2017.11.037. [Link]

Tang, W.-J., K. Yang, J. Qin, C. C. K. Cheng, and J. He, 2011: Solar radiation trend across China in recent decades: A revisit with quality-controlled data. Atmos. Chem. Phys., 11, 393-406, doi: 10.5194/acp-11-3932011. [Link]

Tapiador, F. J., R. Moreno, and A. Navarro, 2019: Consensus in climate classifications for present climate and global warming scenarios. Atmos. Res., 216, 26-36, doi: 10.1016/j.atmosres.2018.09.017. [Link]

Vicente-Serrano, S. M., G. Van der Schrier, S. Beguería, C. Azorin-Molina, and J.-I. Lopez-Moreno, 2015: Contribution of precipitation and reference evapotranspiration to drought indices under different climates. J. Hydrol.,
526, 42-54, doi: 10.1016/j.jhydrol.2014.11.025. [Link] Wang, C., Y. Li, S. W. Myint, Q. Zhao, and E. A. Wentz, 2019: Impacts of spatial clustering of urban land cover on land surface temperature across Köppen climate zones in the contiguous United States. Landsc. Urban Plan., 192, 103668, doi: 10.1016/j.landurbplan.2019.103668. [Link]

Wang, C., D. Cui, and J. Santisirisomboon, 2020: Projected changes in extreme precipitation over eastern Asia in the 21st century. Int. J. Climatol., 40, 3701-3713, doi: 10.1002/joc.6422. [Link]

Wang, Y., X. Shen, M. Jiang, S. Tong, and X. Lu, 2021: Spatiotemporal change of aboveground biomass and its response to climate change in marshes of the Tibetan Plateau. Int. J. Appl. Earth Obs. Geoinf., 102, 102385, doi: 10.1016/j.jag.2021.102385. [Link]

Wei, W., S. Pang, X. Wang, L. Zhou, B. Xie, J. Zhou, and C. Li, 2020: Temperature Vegetation Precipitation Dryness Index (TVPDI)-based dryness-wetness monitoring in China. Remote Sens. Environ., 248, 111957 , doi: 10.1016/j.rse.2020.111957. [Link]

Westerling, A. L., H. G. Hidalgo, D. R. Cayan, and T. W. Swetnam, 2006: Warming and Earlier Spring Increase Western U.S. Forest Wildfire Activity. Science, 313, 940-943, doi: 10.1126/science.1128834. [Link]

Xu, W., C. Sun, J. Zuo, Z. Ma, W. Li, and S. Yang, 2019: Homogenization of Monthly Ground Surface Temperature in China during 1961-2016 and Performances of GLDAS Reanalysis Products. J. Clim., 32, 1121-1135, doi: 10.1175/JCLI-D-18-0275.1. [Link]

Yan, Y., Q. You, F. Wu, N. Pepin, and S. Kang, 2020: Surface mean temperature from the observational stations and multiple reanalyses over the Tibetan Plateau. Clim. Dyn., 55, 2405-2419, doi: 10.1007/s00382-020-053860 . [Link]

Ye, J., F. Li, G. Sun, and A. Guo, 2010: Solar dimming and its impact on estimating solar radiation from diurnal temperature range in China, 1961-2007. Theor. Appl. Climatol., 101, 137-142, doi: 10.1007/s00704-0090213-y. [Link]

Yoo, J. and R. V. Rohli, 2016: Global distribution of Köppen-Geiger climate types during the Last Glacial Maximum, Mid-Holocene, and present. Paleogeogr. Paleoclimatol. Paleoecol., 446, 326-337, doi: 10.1016/j. palaeo.2015.12.010. [Link]

Yu, R., B. Wang, and T. Zhou, 2004: Tropospheric cooling and summer monsoon weakening trend over East Asia. Geophys. Res. Lett., 31, L22212, doi: 10.1029/2004GL021270. [Link]

Yuan, M., L. Wang, A. Lin, Z. Liu, Q. Li, and S. Qu, 2020: Vegetation green up under the influence of daily minimum temperature and urbanization in the Yellow River Basin, China. Ecol. Indic., 108, 105760, doi: 10.1016/j. ecolind.2019.105760. [Link] 
Zarch, M. A. A., B. Sivakumar, H. Malekinezhad, and A. Sharma, 2017: Future aridity under conditions of global climate change. J. Hydrol., 554, 451-469, doi: 10.1016/j.jhydrol.2017.08.043. [Link]

Zhai, J., R. Liu, J. Liu, G. Zhao, and L. Huang, 2014: Radiative forcing over China due to albedo change caused by land cover change during 1990-2010. J. Geogr. Sci., 24, 789-801, doi: 10.1007/s11442-014-1120-4. [Link]

Zhang, A. and G. Jia, 2013: Monitoring meteorological drought in semiarid regions using multi-sensor microwave remote sensing data. Remote Sens. Environ., 134, 12-23, doi: 10.1016/j.rse.2013.02.023. [Link]

Zhang, X. and X. Yan, 2014: Spatiotemporal change in geographical distribution of global climate types in the context of climate warming. Clim. Dyn., 43, 595-605, doi: 10.1007/s00382-013-2019-y. [Link]

Zhao, X., J. Liu, Q. Liu, M. R. Tillotson, D. Guan, and K. Hubacek, 2015: Physical and virtual water transfers for regional water stress alleviation in China. Proc. Natl. Acad. Sci. U. S. A., 112, 1031-1035, doi: 10.1073/ pnas.1404130112. [Link]

Zhou, D., D. Li, G. Sun, L. Zhang, Y. Liu, and L. Hao, 2016: Contrasting effects of urbanization and agriculture on surface temperature in eastern China. J. Geophys. Res., 121, 9597-9606, doi: 10.1002/2016JD025359. [Link]

Zou, X., P. Zhai, and Q. Zhang, 2005: Variations in droughts over China: 1951-2003. Geophys. Res. Lett., 32, L04707, doi: 10.1029/2004GL021853. [Link] 